\title{
Inter-row tillage for improved soil and water conservation and crop yields on crusted Alfisols
}

\author{
Prabhakar Pathak*, Suhas P. Wani, Raghavendra Sudi, Nagaraju Budama \\ Resilient Dryland Systems, International Crops Research Institute for the Semi-Arid Tropics (ICRISAT), Hyderabad, India; \\ *Corresponding Author: p.pathak@,cgiar.org
}

Received 21 May 2013; revised 21 June 2013; accepted 20 July 2013

Copyright (C) 2013 Prabhakar Pathak et al. This is an open access article distributed under the Creative Commons Attribution License, which permits unrestricted use, distribution, and reproduction in any medium, provided the original work is properly cited.

\section{ABSTRACT}

In the semi-arid tropics (SAT), $33 \%$ areas are occupied by Alfisols and related soils. In SAT these soils have low structural stability and thereby tend to form seal and crusts at the surface. Due to this a large proportion of the rain that falls on Alfisols during the early part of the rainy season, is normally lost as runoff thus causing high soil loss as well as moisture stress to crops. Two tillage studies were conducted first at plot scale $\left(320 \mathrm{~m}^{2}\right)$ during 1991-95 and second at small watershed scale (1.45 ha) during 2007-10, at ICRISAT research station, Hyderabad, India. These studies were conducted to find out whether the problem of excessive runoff and soil loss during the early part of the rainy season can be controlled by various inter-row tillage systems in addition to normal intercultivation by breaking the crust or seal and thereby improving infiltration and soil moisture and reducing runoff and soil loss. The observations on rainfall, runoff, soil moisture, soil loss, soil surface roughness and crop yields were collected from both the studies. Results from these studies have shown that inter-row tillage in addition to normal intercultivation is found effective in controlling early season runoff and soil loss and increasing crop yields. The additional tillage systems are found most effective during low and medium rainfall years and not so much during high rainfall years. The additional tillage with shoe cultivators, which creates rough soil surface $(11 \mathrm{~mm}$ depression storage), is found most effective in increasing crop yields and reducing runoff and soil loss. The additional tillage with blade harrow which generates smooth soil surface is relatively less effective. In most rainfall conditions, the normal intercultivation with one additional tillage is found adequate for controlling early season runoff and improving soil moisture and crop yields.

Keywords: Runoff; Soil Loss; Crusting; Sealing; Semi-Arid Tropics; Alfisols; Soil Surface Roughness

\section{INTRODUCTION}

Alfisols are important soils in the semi-arid tropics (SAT), covering nearly $33 \%$ of the SAT region. With their poor water retention characteristics, rainfed cropping of Alfisols is ever threatened with deficient soil moisture conditions even in relatively short dry spells. This situation is further exacerbated by crust and seal forming at the soil surface, resulting in very low infiltration even under dry soil conditions [1,2]. Crusting and sealing on cultivated SAT Alfisols are among the primary causes of low infiltration, poor crop stands and excessive runoff and soil loss [3-6]. The "inert" mineral composition of Alfisols and their lack of inter particle bonding because of low organic matter content and unstable soil aggregation together with conventional system of farming increase the potential for soil surface sealing and crusting $[7,8]$. Usually the inherent structural instability of Alfisols is not restricted to the immediate surface but often extends to the entire cultivated soil layer [9]. Therefore, the cultivated soil layer may often be prone to slumping and hardening thus reducing rainwater infiltration and making the timely subsequent tillage difficult. Due to these soil related factors and other constraints, low productivity and even crop failure are a common fact which discourages farmers from making substantial investments for improved management. On Alfisols, the problems of surface sealing, crusting and slumping have been observed more during the early part of the crop growing season because of sparse vegetation and poor crop canopy, which does not provide effective protection 
against the rainfall impact $[7,10,11]$. Consequently, major part of the rain that falls during the early part of season on Alfisols, is often lost as runoff which in turn causes appreciable soil loss and moisture stress [10]. This shedding of water occurs even when the soil profile is relatively dry. Several approaches have been suggested to address the problem of poor infiltration during early part of the rainy season on SAT Alfisols. One such approach is to use the management systems viz. conservation tillage and others, which in the long-term could improve the Alfisol structure. Improved soil structure is expected to provide long-term solution to this problem of crusting and sealing on SAT Alfisols. However, most of the research findings with such management systems for SAT Alfisols have not been conclusive and also the possibility of adoption of such technologies by SAT farmers is expected to be very low. The other approach to alleviate this problem on SAT Alfisols could be to till the soil in order to break the crusts and seals and loosen the top soil before it becomes too compact and hard. This paper discusses the results from the experiments as well as simulation modeling on the effectiveness of various inter-row tillage systems in controlling runoff, soil loss and in increasing crop yields on Alfisols.

\section{MATERIALS AND METHODS}

\subsection{Location and Climate}

The experiments were conducted on Alfisols at the ICRISAT center farm in Patancheru, near Hyderabad, India $\left(17^{\circ} 36^{\prime} \mathrm{N}, 78^{\circ} 16^{\prime} \mathrm{E}, 545 \mathrm{~m}\right.$ altitude). The mean annual rainfall at the experimental station is about $892 \mathrm{~mm}$; the average minimum temperature is $17^{\circ} \mathrm{C}$ and maximum temperature is $32^{\circ} \mathrm{C}$. Rainfall is variable spatially and temporally; and often occurs in high intensity. About $80 \%$ of the annual rainfall occurs during four months (June-September) termed rainy season, and this period is used for growing crops under rainfed conditions. The post-rainy season (October-January) is dry and the days are cool and short.

\subsection{Soils}

Alfisols at the experimental sites are reddish brown, derived from pink granites, and belong to the isohyperthermic family of Udic Rhodhustalfs. Some of the major physical and chemical characteristics of these soils are given in Table 1. These soils are well drained, and have sandy loam to sandy clay loam texture at the surface. They have very low water retention characteristics; and have mechanical impedance-related problems in the soil profile that restrict crop root development and proliferation. The soil has an unstable structure mainly due to low contents of fine (clay-sized) particles and inactivity of the prevailing clay minerals (mostly kaolin). A major consequence of the lack or non-stability of aggregation is the tendency of these soils to display rapid surface sealing following rainfall and crusting with subsequent drying. This characteristic greatly influences the infiltration, runoff and soil loss behavior of these soils. Sub-surface layers are very hard and compact, and possess relatively lower saturated hydraulic conductivity. The soils are very low in organic matter and the depth of these soils at the experimental sites range from 80 to $110 \mathrm{~cm}$.

\subsection{Experimental Details}

The tillage experiments were conducted first at plot

Table 1. Major characteristics of Alfisols in the experimental site at the ICRISAT farm in Patancheru, India.

\begin{tabular}{|c|c|c|c|c|c|c|c|c|c|c|}
\hline \multirow{2}{*}{$\begin{array}{c}\text { Soil } \\
\text { depth }(\mathrm{cm})\end{array}$} & \multirow{2}{*}{$\begin{array}{c}\text { Clay sand } \\
(<0.002 \mathrm{~mm})\end{array}$} & \multirow{2}{*}{$\begin{array}{c}\text { Silt } \\
(0.050-0.002 \mathrm{~mm})\end{array}$} & \multirow{2}{*}{$\begin{array}{c}\text { Sand } \\
(2-0.05 \mathrm{~mm})\end{array}$} & \multirow{2}{*}{$\begin{array}{l}\text { Coarse fragments } \\
\qquad(>2 \mathrm{~mm})\end{array}$} & \multicolumn{4}{|c|}{ Moisture holding capacity (\%) } & \multirow{2}{*}{\multicolumn{2}{|c|}{$\begin{array}{l}\text { Bulk density } \\
\left(\mathrm{g} \cdot \mathrm{cm}^{-3}\right)\end{array}$}} \\
\hline & & & & & \multicolumn{2}{|c|}{$0.03 \mathrm{MPa}$} & \multicolumn{2}{|c|}{$1.5 \mathrm{MPa}$} & & \\
\hline $0-15$ & 13.2 & 6.1 & 75.7 & 5.0 & \multicolumn{2}{|c|}{13} & \multicolumn{2}{|c|}{7.2} & \multicolumn{2}{|c|}{1.50} \\
\hline $15-30$ & 22.3 & 9.7 & 63.0 & 6.0 & \multicolumn{2}{|c|}{18} & \multicolumn{2}{|c|}{10.1} & \multicolumn{2}{|c|}{1.58} \\
\hline $30-60$ & 31.1 & 9.0 & 51.9 & 8.0 & \multicolumn{2}{|c|}{21} & & & \multicolumn{2}{|c|}{1.59} \\
\hline $60-90$ & 38.3 & 8.8 & 41.9 & 12.0 & \multicolumn{2}{|c|}{23} & & & \multicolumn{2}{|c|}{1.46} \\
\hline \multirow{2}{*}{$\begin{array}{l}\text { Soil depth } \\
\quad(\mathrm{cm})\end{array}$} & \multirow{2}{*}{$\begin{array}{c}\text { Organic carbon } \\
(\%)\end{array}$} & \multirow{2}{*}{$\begin{array}{c}\mathrm{pH}(1: 2: 5) \mathrm{H}_{2} \mathrm{O} \\
\text { suspension }\end{array}$} & \multirow{2}{*}{$\begin{array}{c}\mathrm{EC}(1: 2: 5) \mathrm{H}_{2} \mathrm{O} \\
\text { Suspension }(\mathrm{dS} / \mathrm{m})\end{array}$} & \multirow{2}{*}{$\begin{array}{c}\mathrm{CEC} \\
\mathrm{NH}_{4} \mathrm{OA}_{\mathrm{c}} \\
(\mathrm{cmol} / \mathrm{kg})\end{array}$} & \multirow{2}{*}{$\begin{array}{c}\text { Base } \\
\text { saturation } \\
(\%)\end{array}$} & \multicolumn{5}{|c|}{ Clay fraction mineralogy ${ }^{\mathrm{b}}$} \\
\hline & & & & & & $\mathrm{AM}$ & KK & MI & SM & QZ \\
\hline $0-15$ & 0.53 & 6.5 & 0.1 & 6.2 & 70 & 11 & 37 & 11 & 17 & 15 \\
\hline $15-30$ & 0.52 & 6.6 & 0.1 & 10.4 & 67 & 12 & 37 & 10 & 19 & 14 \\
\hline $30-60$ & 0.57 & 6.7 & 0.1 & 12.1 & 68 & 14 & 37 & 10 & 23 & 13 \\
\hline $60-90$ & 0.45 & 6.5 & 0.1 & 12.3 & 74 & 12 & 38 & 11 & 20 & 16 \\
\hline
\end{tabular}

${ }^{\mathrm{b}} \mathrm{AM}=$ amphibole; $\mathrm{KK}=$ kaolinite; $\mathrm{MI}=$ mica; $\mathrm{SM}=$ Smectite; $\mathrm{QZ}=$ quartz. 
scale $\left(320 \mathrm{~m}^{2}\right)$ and then at small watershed scale $(1.45$ ha). The plot level experiment was conducted during 1991-95 on 12 plots $(8 \times 40 \mathrm{~m})$ to compare three interrow tillage systems: 1) normal intercultivation; 2) normal intercultivation plus one additional inter-row tillage with blade harrow and 3) normal intercultivation plus one additional tillage with shoe cultivators of rain-water. The watershed scale experiments were carried out during 2007-2010 on two small watersheds (1.45 ha). The timing of normal intercultivation was based on the need to control weeds, while the timing in additional inter-row tillage was based on crust or seal formation at the soil surface.

In both field and watershed scale experiments, the crops of sorghum and sorghum intercropped with pigeon pea were grown on yearly rotation. The crops were sown in June-July after the rains had wetted the top $0-20 \mathrm{~cm}$ soil profile. The inter-row tillage with blade harrow generally leaves a smooth soil surface with very fine pulverized soil, while the shoe type cultivations make very rough and cloddy soil surface with good depressions.

\subsection{Measurements and Analysis}

\subsubsection{Measurement and Data Analysis}

In the watershed scale experiment, the surface runoff was measured by using 2 feet $\mathrm{H}$-flume and digital stagelevel recorders. In the digital stage-level recorder, the changes in the water level are transferred via float cable and counter weight system to the float pulley on the shaft encoder unit. In this equipment, the sampling and logging intervals of stage were set to 1 and 6 minutes intervals, respectively. The stage vs time graph was subsequently processed using H-flume calibrated chart to obtain the runoff volume. For measuring soil loss, runoff samples from each runoff events were collected using a microprocessor based automatic runoff samplers [12]. These automatic runoff samplers collected and stored samples in separated containers at 10-minute time intervals through out the runoff events. These samples were analyzed in laboratory for sediment concentration of eroded soil material. The concentration values were used to prepare sediment concentration vs time graph, which was superimposed on the runoff hydrograph. Each runoff event hydrograph was divided into 10-minute time segments. For each hydrograph segment, the soil loss was computed by multiplying the segment runoff volume with sediment concentration. The total soil loss for a runoff event was determined by adding these segment values.

The rainfall amount and its intensity were monitored by using tipping bucket rain gauge with a bucket resolution of $0.254 \mathrm{~mm}$ per tip. The number of tips vs time date are stored in the data logger and reported as rainfall in $\mathrm{mm}$ at a four-minute interval.

In the plot scale experiment, the runoff was measured using $\mathrm{V}$ notch and mechanical chart type liquid level recorder. During each runoff event, runoff samples at a regular interval of 15 minutes were collected manually to estimate the sediment concentrations, which were then used to estimate the total storm soil loss. The soil surface roughness was measured by using pin type relief meter. The measurement on soil surface roughness was taken after every tillage operation as well as after every major rainfall events. These values were used to estimate the soil surface roughness capacity.

The watershed scale experiment was conducted only with normal intercultivation tillage treatment and the data are runoff, soil loss, and crop yields were collected. For other two treatments viz. normal intercultivation plus one additional tillage with shoe cultivators and normal inter cultivation plus two additional tillage with shoe cultivators were simulated using runoff model [13] and crop yield model [14]. The runoff and soil loss data from the field scale experiment during 1991-95 were used to modify, calibrate and test the runoff and water balance model [13].

\subsubsection{Simulating Inter-Row Tillage Effects on Various Parameters}

To simulate the inter-row tillage effects on runoff and soil loss on crusted Alfisols, one subroutine on surface roughness has been added to the runoff model by [13]. Immediately after the inter-row tillage the value of soil surface roughness is highest, which is gradually reduced by the subsequent rainfalls (raindrop impact) and runoff flow. The soil surface roughness subroutine estimates the daily soil surface roughness values based on rainfall, runoff and other soil and crop parameters. These values are finally used to correct the simulated runoff, soil moisture and soil loss values. Two factors are mainly responsible for changes in the soil surface roughness and these are rainfall energy (raindrop impact) and runoff flow energy. In the model subroutine on soil surface roughness, the rainfall energy for each rainfall event is estimated by following equation:

$$
R_{E}=R\left(k_{1} \log r_{m}+k_{2} \log r_{p}\right)
$$

where

$R_{E}=$ Rainfall energy for changes in the soil surface roughness;

$R=$ Daily rainfall;

$r_{m}=$ Weighted mean rainfall intensity;

$r_{p}=$ Peak rainfall intensity for 30 minutes;

$k_{1}$ and $k_{2}=$ Constants derived from the calibration from the observed values.

The runoff flow energy for smoothing the soil surface roughness is estimated by the following Equation (2): 


$$
R U_{E}=R U(1.3+2.3 \log S L)
$$

where

$R U_{E}=$ Runoff flow energy for changes in the soil surface roughness;

$R U=$ Runoff volume;

$S L=$ Slope.

Both the rainfall energy $\left(R_{E}\right)$ and runoff flow energy $\left(R U_{E}\right)$ are then used to estimate the soil surface roughness factor, which is estimated by using the following Equation (3):

$$
S S R_{f}=S C F_{f}\left\{c_{1} R_{E}+c_{2} R U_{E}\right\}
$$

where

$S S R_{f}=$ Soil surface roughness factor;

$S C F_{f}=$ Soil coarse fragment factor $\left(S C F_{f}\right.$ indicates the susceptibility of surface soil to rainfall and runoff flow energy. Higher the coarse soil particles, higher is the soil susceptibility to rainfall and runoff energy means much faster reduction in soil surface roughness);

$c_{1}$ and $c_{2}=$ Constants derived from the calibration.

The soil coarse fragment factor $\left(S C F_{f}\right)$ is estimated by using Equation (4):

$$
S C F_{f}=\exp \left(0.03 S C_{f}\right)
$$

where

$S C_{f}$ is the percent of coarse fragment in the surface soil layer.

The soil surface roughness factor is then adjusted to surface soil conditions (bulk density etc). This is done by the following Equation (5):

$$
S S R C_{f}=S S R_{f} / t^{*}
$$

where

$S S R C_{f}$ is the actual soil surface roughness correction and $t^{*}$ is time decay factor. The value of $t^{*}$ depends on the tillage date and subsequent rainfall and runoff events. After the tillage for the first rainy day the value of $t^{*}$ will be 1 and for $2^{\text {nd }}, 3^{\text {rd }}, \ldots, n^{\text {th }}$ rainy days the value of $t^{*}$ will be $2,3, \ldots, n$. if there is no rain the value of $t^{*}$ will remain constant and there will be no change in $t^{*}$ values.

\section{RESULTS AND DISSCUSSIONS}

\subsection{Plot Scale Experiment}

\subsubsection{Runoff and Soil Loss}

The annual runoff was significantly influenced by different inter-row tillage systems (Table 2). The annual runoff data of four years (1991-94) clearly show that the

Table 2. Effects of different inter-row tillage systems on runoff and soil loss from small plot experiment on Alfisols, ICRISAT Center, 1991-95.

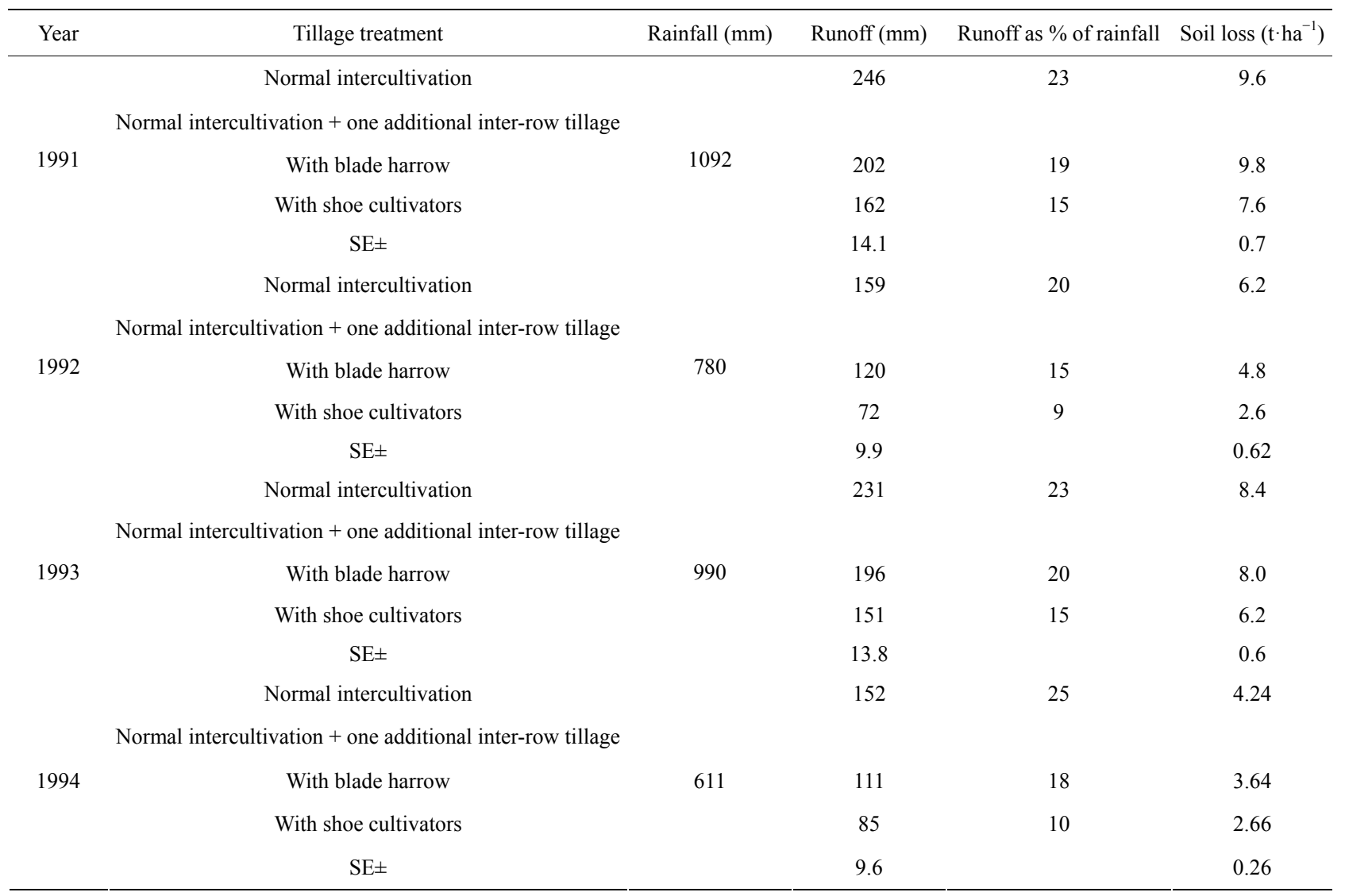


additional inter-row tillage treatments are quite effective in reducing runoff compared to the normal intercultivation tillage. Among the tillage systems, the additional tillage with shoe cultivators is found to be most effective in reducing annual runoff. The reduction in annual runoff by one additional tillage with shoe cultivators compared to normal intercultivation ranged from $34 \%$ in high rainfall years (1991 and 1993) to 55\% in a normal rainfall year (1992). Even during a low rainfall year (1994), this additional tillage systems reduced the annual runoff by $44 \%$ (85 vs $152 \mathrm{~mm}$ runoff) compared to normal intercultivation tillage. Similar trend, but of much lower magnitude, in annual runoff reduction was observed for additional tillage with blade harrow. The decrease in annual runoff by this tillage system compared to normal intercultivation tillage ranged from $17 \%$ during high rainfall years (1991 and 1993) to $27 \%$ during low rainfall year (1994). During normal rainfall year (1992), this additional tillage system was quite effective in reducing annual runoff (120 vs $159 \mathrm{~mm}$ ) compared to normal intercultivation. These data clearly show that both the additional inter-row tillage systems are quite effective in reducing annual runoff particularly during low and normal rainfall years. However, their effectiveness in reducing annual runoff during high rainfall years is limited. The higher reduction in runoff due to additional interrow tillage during the normal and low rainfall years is highly desirable because generally in such years, crops suffer most from moisture stress and therefore any additional rainfall infiltration under these rainfall situations would be highly beneficial to the crops. The low effecttiveness of additional inter-row tillage in reducing runoff during the high rainfall years may not be so disadvantageous because the benefits to crops due to additional rainfall infiltration in such rainfall years may not be substantial and indeed may lead to waterlogging and excessive nutrients leaching losses.

The daily runoff recorded from the different tillage treatments during the experimental period (1991-94) clearly show that most of the differences in the runoff between the various tillage treatments were during first 6 - 7 weeks of the cropping season in which additional inter-row tillage was done. After 6 - 7 weeks (around mid August), the runoff from most tillage treatments are similar. This is supported by the data on soil surface roughness, which were collected during the cropping season from the different tillage treatments (Figure 1). The soil surface roughness data from the different tillage treatments show that during the early part of rainy season the soil surface depression storage values are significantly higher in the additional tillage treatments compared to normal intercultivation treatment (Figure 1). However, during the later parts of the rainy season (after mid-August) the soil surface roughness storage values are not significantly different among the various tillage treatments. It is important to mention that the soil surface roughness plays a very important role in reducing runoff and increasing infiltration on crusted soils. It allows temporary storage of runoff water in the small depressions and provides longer time for runoff water to infiltrate into soil profile. Generally, higher the soil surface roughness better is for rainwater conservation.

The annual soil loss from the different tillage treatments showed slightly different trend from those observed for annual runoff (Table 2). The effectiveness of two additional inter-row tillage treatments in reducing annual soil loss has been mixed. Compared to normal intercultivation, both additional inter-row tillage treatments reduced the annual soil loss, however, their effecttiveness varied considerably during low, medium and high rainfall years. Among the treatments, the additional tillage with shoe cultivators is found to be most effective in reducing annual soil loss. Compared to normal intercultivation this tillage system reduced the annual soil loss by $37 \%, 58 \%$ and $24 \%$ during low, medium and high rainfall years respectively. During low and medium rain-

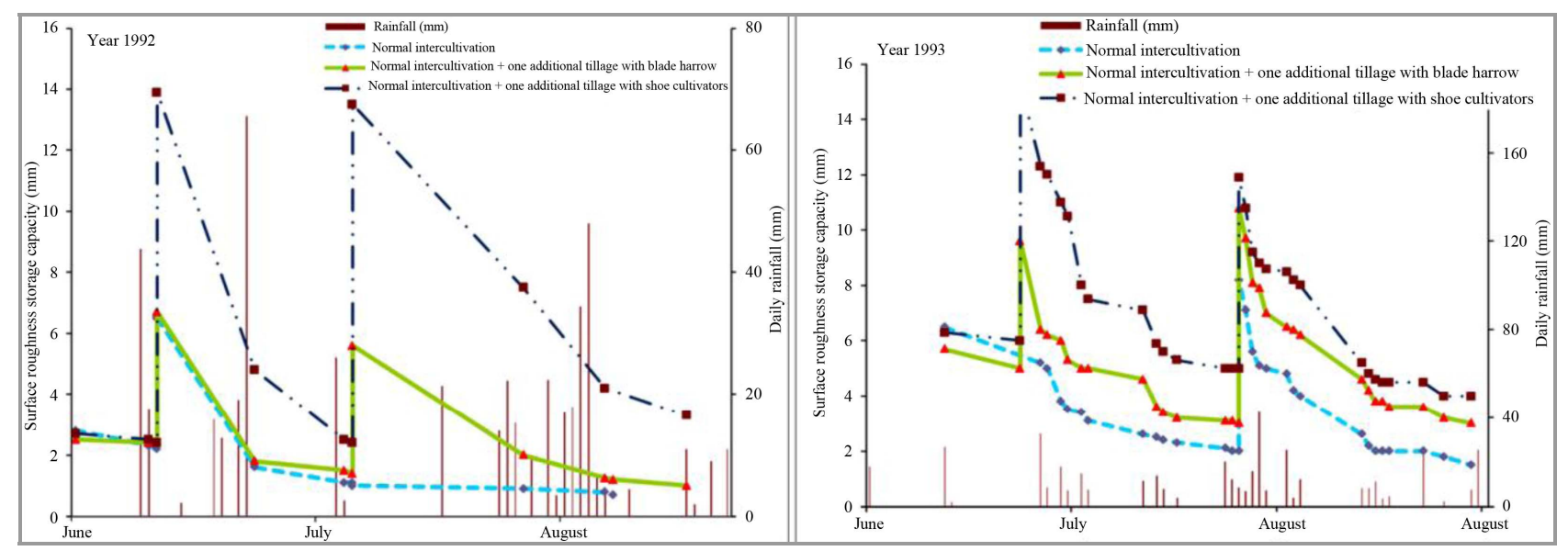

Figure 1. Changes in the surface depression storage capacity from different inter-row tillage systems on Alfisols during $1992-1993$. 
fall years, this tillage system is found highly effective in reducing soil loss. The additional tillage with blade harrow is found moderately effective in reducing soil loss. Compared to normal intercultivation, this tillage system reduced the annual soil loss by $14 \%, 26 \%$ and $1 \%$ during low, medium and high rainfall years respectively (Table 2). During high rainfall years (1991 and 1993), this tillage system was not effective in reducing soil loss. In fact, during one high rainfall year (1991), this tillage system recorded higher soil loss by $2.1 \%$ compared to normal intercultivation. During all rainfall conditions particularly in the high rainfall years, the sediment concentration (soil loss per unit of runoff) was found to be higher in additional tilled plots compared to plots with normal intercultivation. Even for additional tillage with shoe cultivators, which had significantly low soil loss compared to normal intercultivation, the sediment concentration was significantly higher. This indicates that the reduction in soil loss due to additional tillage is mainly due to its effects on reducing runoff amount.

On Alfisols, controlling soil erosion is highly desirable. This is because most of Alfisols in the SAT regions are poor in terms of physical, chemical and biological soil health parameters. Any further land degradation due to soil erosion is highly undesirable and may eventually lead to low as well as unstable agricultural productivity [10].

\subsubsection{Crop Yields}

In three out of four years, the additional tillage treatments have significantly increased the rainy season crop yields compared to normal intercultivation tillage (Table 3). However, the additional tillage treatments are found effective in increasing crop yields mainly of rainy season crops. It has limited effect on increasing yield of relatively long-duration crop like pigeonpea. Among the treatments, the additional tillage with shoe cultivators is found to be most effective in increasing yield of rainy season crops. Compared to normal intercultivation this tillage treatment increased the sorghum yields by $31.4 \%$ (1.72 vs $2.26 \mathrm{t} \cdot \mathrm{ha}^{-1}$ ) and $30.5 \%$ (2.26 vs $\left.2.95 \mathrm{t} \cdot \mathrm{ha}^{-1}\right)$ during low and medium rainfall years respectively. Even during high rainfall years (1993), this tillage system increased the pearl millet yield by $16 \%$ (2.62 vs 3.04 $\mathrm{t} \cdot \mathrm{ha}^{-1}$ ) compared to normal intercultivation system. Similar trend, but of much lower magnitude in increasing crop yields, is observed for additional tillage with blade harrow. Compared to normal intercultivation, this tillage system increased the sorghum yield by $19.2 \%$ (1.72 vs $2.05 \mathrm{t} \cdot \mathrm{ha}^{-1}$ ) and $15.9 \%$ (2.26 vs $\left.2.62 \mathrm{t} \cdot \mathrm{ha}^{-1}\right)$ during low and medium rainfall years, respectively. Better performance of additional tillage treatments in increasing crop yields could mainly be due to increased infiltration, which must have provided better moisture environment for plant growth. Other reason could be that due to additional tillage weed infestation was less in the plots that received additional tillage. In some years during extended rainless periods, the additional tillage resulted in reduced evaporation loss by creating dust mulch at the soil surface thereby improving soil moisture status. The observation during the extended rainfall periods of 1992 , 1993 and 1994 indicate that the moisture content in top $20 \mathrm{~cm}$ soil profile was higher by $12 \%-21 \%$ in plots where additional tillage were done.

\subsection{Watershed Scale Experiment}

\subsubsection{Runoff and Soil Loss}

Large differences can be seen in the annual runoff between the tillage systems (Table 4). The highest mean annual runoff is recorded from the normal intercultivation treatment $(151 \mathrm{~mm})$, followed by one additional tillage $(108 \mathrm{~mm})$, and the lowest runoff was observed in two additional tillage treatment $(101 \mathrm{~mm})$. During all experimental years (2007-10), the additional tillage treatment is found effective in reducing annual runoff

Table 3. Effects of different inter-row tillage systems on grain yield from small plot experiments on Alfisols, ICRISAT Center 1991-95.

\begin{tabular}{|c|c|c|c|c|c|c|}
\hline \multirow{4}{*}{ Tillage treatment } & \multicolumn{6}{|c|}{ Grain yield $\left(\mathrm{t} \cdot \mathrm{ha}^{-1}\right)$} \\
\hline & 1991 & \multicolumn{2}{|c|}{$1992-93$} & 1993 & \multicolumn{2}{|c|}{$1994-95$} \\
\hline & \multirow{2}{*}{ Sole sorghum } & \multicolumn{2}{|c|}{ Intercrop } & \multirow{2}{*}{$\begin{array}{l}\text { Sole pearl } \\
\text { millet }\end{array}$} & \multicolumn{2}{|c|}{ Intercrop } \\
\hline & & Sorghum & Pigeonpea & & Sorghum & Pigeonpea \\
\hline Normal intercultivation & 2.35 & 2.26 & 0.93 & 2.62 & 1.72 & 0.45 \\
\hline \multicolumn{7}{|l|}{$\begin{array}{l}\text { Normal intercultivation }+ \text { one } \\
\text { additional inter-row tillage }\end{array}$} \\
\hline With blade harrow & 2.36 & 2.62 & 0.93 & 2.97 & 2.05 & 0.48 \\
\hline With shoe cultivators & 2.40 & 2.95 & 1.03 & 3.04 & 2.26 & 0.50 \\
\hline $\mathrm{SE} \pm$ & 0.12 & 0.11 & 0.06 & 0.10 & 0.16 & 0.12 \\
\hline
\end{tabular}


Table 4. Effects of different inter-row tillage systems on runoff and soil loss from Alfisol watershed experiment, ICRISAT Center, Patancheru, India, 2007-10.

\begin{tabular}{|c|c|c|c|c|}
\hline Year & Tillage treatment & Rainfall (mm) & Runoff $(\mathrm{mm})^{*}$ & Soil loss $\left(\mathrm{t} \cdot \mathrm{ha}^{-1}\right)^{*}$ \\
\hline \multirow{3}{*}{2007} & Normal intercultivation & \multirow{3}{*}{581} & 80.3 & 2.11 \\
\hline & Normal intercultivation + one additional tillage with shoe cultivators & & 43.3 & 1.52 \\
\hline & Normal intercultivation + two additional tillage with shoe cultivators & & 34.0 & 1.21 \\
\hline \multirow{3}{*}{2008} & Normal intercultivation & \multirow{3}{*}{846} & 133 & 5.19 \\
\hline & Normal intercultivation + one additional tillage with shoe cultivators & & 82.3 & 4.29 \\
\hline & Normal intercultivation + two additional tillage with shoe cultivators & & 77.5 & 4.62 \\
\hline \multirow{3}{*}{2009} & Normal intercultivation & \multirow{3}{*}{760} & 114.7 & 5.96 \\
\hline & Normal intercultivation + one additional tillage with shoe cultivators & & 68.3 & 3.96 \\
\hline & Normal intercultivation + two additional tillage with shoe cultivators & & 61.7 & 3.15 \\
\hline \multirow{3}{*}{2010} & Normal intercultivation & \multirow{3}{*}{1071} & 274.1 & 6.30 \\
\hline & Normal intercultivation + one additional tillage with shoe cultivators & & 238.0 & 5.20 \\
\hline & Normal intercultivation + two additional tillage with shoe cultivators & & 229.6 & 5.96 \\
\hline
\end{tabular}

*Other than normal intercultivation all other treatments values are simulated.

compare to normal intercultivation. However, their effectiveness during low (2007) and medium rainfall years (2008 and 2009) is significantly higher compare to high rainfall year (2010). The two additional tillage with shoe cultivators is found to be most effective in reducing annual runoff. Compared to normal intercultivation, this tillage system reduced the annual runoff by $51 \%, 44 \%$ and 16\% during low (2007), medium (2008 and 2009) and high rainfall years (2010), respectively. Similar trend, but of slightly lower magnitude in runoff reduction is observed for the treatment of one additional tillage with shoe cultivators. Compared to normal intercultivation, this tillage treatment reduced the annual runoff by $46 \%$, $39 \%$ and $13 \%$ during low, medium and high rainfall years, respectively. These data clearly show that both the additional tillage systems are effective in reducing annual runoff particularly during low and medium rainfall years. However, these treatments are not so effective in reducing annual runoff during high rainfall years.

Among the additional tillage treatments, very small differences in annual runoff can be seen (Table 4). For example, in medium rainfall years (2008 and 2009), the mean annual runoff difference between the additional tillage treatments is only $5.7 \mathrm{~mm}(69.6 \mathrm{vs} 75.3 \mathrm{~mm})$. Also during low and high rainfall years, very small difference between the additional tillage treatments can be seen. The daily runoff recorded during the four experimental years (2007-10) clearly show (Figure 2) that most of the differences in runoff between the various tillage treatments occurred mainly during the early part of rainy season; and it is closely linked to timing and number of additional tillage done. It also reconfirms that there is significant difference in daily and cumulative runoff between the normal intercultivation and additional tillage treatments. However, the differences among the additional tillage treatments are very small. The simulated soil surface roughness values (Figure 3) from the different tillage treatments during 2007-10 support the daily and cumulative runoff values (Figure 2). Closely observing the daily runoff values in Figure 2 and corresponding soil surface roughness values in Figure 3 indicates the importance of soil surface roughness in controlling surface runoff.

The large differences in annual soil loss from the tillage treatments can be seen (Table 4). The highest mean annual soil loss of $4.9 \mathrm{t} \cdot \mathrm{ha}^{-1}$ was recorded from the normal intercultivation treatment, followed by both additional tillage treatments of $3.7 \mathrm{t} \cdot \mathrm{ha}^{-1}$. This shows that the additional tillage system is not only effective in reducing runoff, but also soil loss. However, the effectiveness of both additional tillage treatments in reducing annual soil loss has been quite different during different rainfall conditions. Compared to normal intercultivation, the two additional tillage treatments reduced the annual soil loss by $43 \%, 29 \%$ and $5 \%$ during low, medium and high rainfall years, respectively. Similar trend was observed for the one additional tillage treatment. During low and medium rainfall years, both additional tillage treatments are found highly effective in reducing annual soil loss. During high rainfall year (2010), only treatment with one additional tillage is found effective in reducing annual soil loss. The treatment with two additional tillage is not 


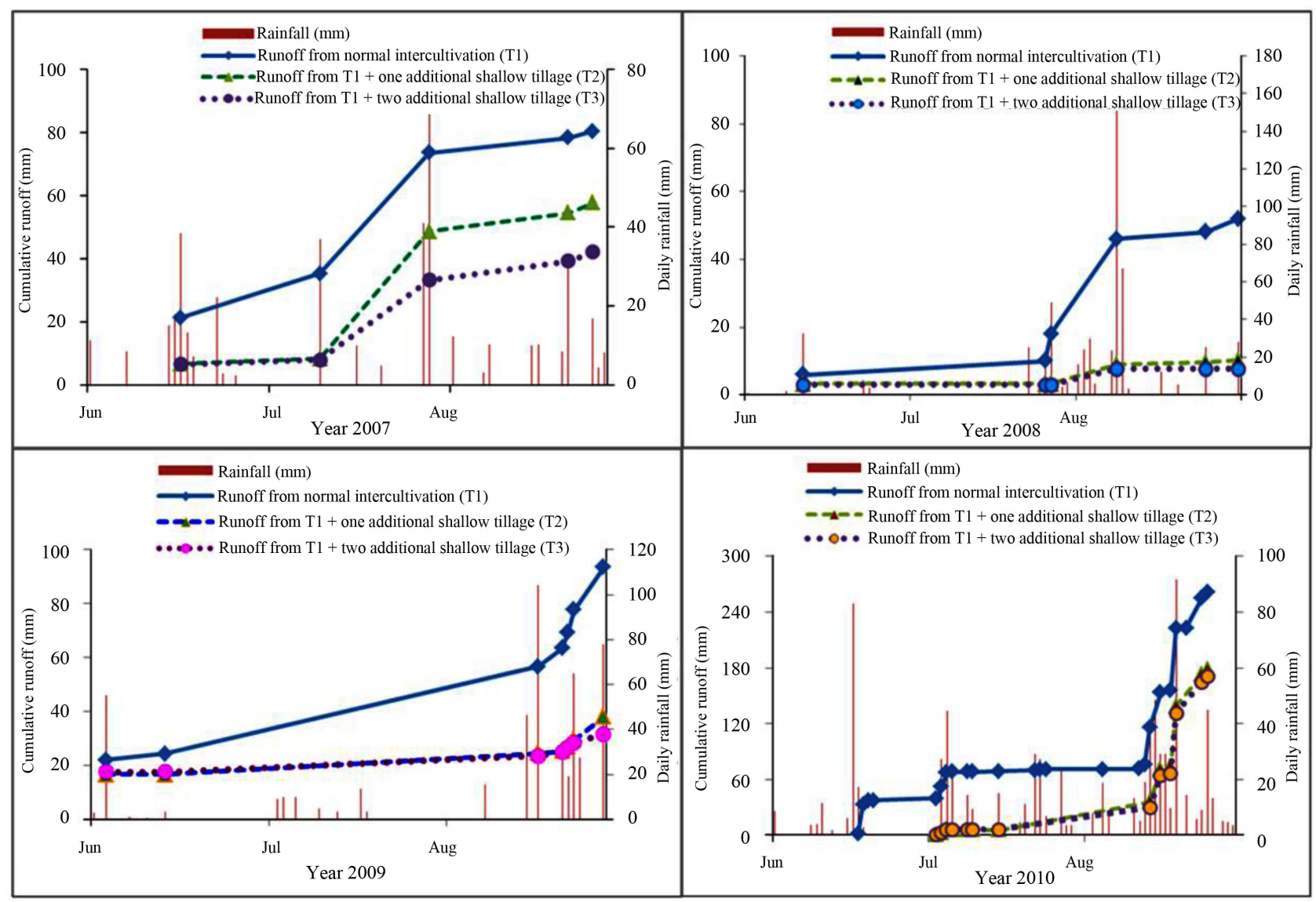

Figure 2. Effects of different shallow inter-row tillage systems on early season runoff from Alfisol watershed during 2007-10, ICRISAT center, Hyderabad, India.

so effective in reducing annual soil loss compared to normal intercultivation (5.96 vs $6.30 \mathrm{t} \cdot \mathrm{ha}^{-1}$ ). During all four experimental years (2007-10), the sediment concentration values in runoff water were significantly higher in additional tillage plots compared normal intercultivation plots. This was particularly true for treatment with two additional tillage treatment. Comparison of runoff and soil loss values from the plot and watershed scale experiments, points the effect of scale. The mean annual runoff and soil loss from the watershed scale experiment are significantly lower compared to plot scale experiments. For example, the mean annual runoff from the normal intercultivation treatment is significantly lower in watershed scale compared to plot scale experiment (150 vs $197 \mathrm{~mm}$ ). Similar trend in runoff is observed for the additional tillage treatments. However, the major effect of scale can be seen in the soil loss values recorded from the watershed and plot scale experiments. In the normal intercultivation treatment, the mean annual soil loss is reduced by $48 \%$ ( 4.9 vs $7.1 \mathrm{t} \cdot \mathrm{ha}^{-1}$ ) in the watershed scale compared plot scale experiments. Similar trend in soil loss is recorded for the additional tillage treatments. This highlights that the plot scale soil loss values are not very realistic.

\subsubsection{Crop Yield}

During all the four years of experimentation (2007-10), the additional tillage treatment gave significantly higher sorghum yield compared to normal intercultivation (Table 5). On average, the one and two additional tillage treatments increased the sorghum yield by $15.1 \%(2.89$ vs $\left.2.51 \mathrm{t} \cdot \mathrm{ha}^{-1}\right)$ and $19.5 \%\left(3.00\right.$ vs $\left.2.51 \mathrm{t} \cdot \mathrm{ha}^{-1}\right)$, respectively compared to normal intercultivation. However, the effectiveness of both additional tillage systems in increasing sorghum yield varied considerably under different rainfall conditions. The additional tillage treatments are found most effective in increasing sorghum yields during low rainfall year (2007), followed by medium rainfall years (2008 and 2009) and least during high rainfall year (2010). During the low rainfall year (2007) the one and two additional tillage treatments increased the sorghum yield by $26.1 \%$ (2.66 vs $\left.2.11 \mathrm{t} \cdot \mathrm{ha}^{-1}\right)$ and $37.0 \%$ (2.89 vs $\left.2.11 \mathrm{t} \cdot \mathrm{ha}^{-1}\right)$, respectively compared to normal intercultivation. Similar trend but of lower magnitude in increasing crop yields is observed during the medium rainfall years (2008 and 2009). During the high rainfall year (2010), the additional tillage treatment marginally increased the sorghum yield compared to normal intercultivation. These results reconfirm the trend 


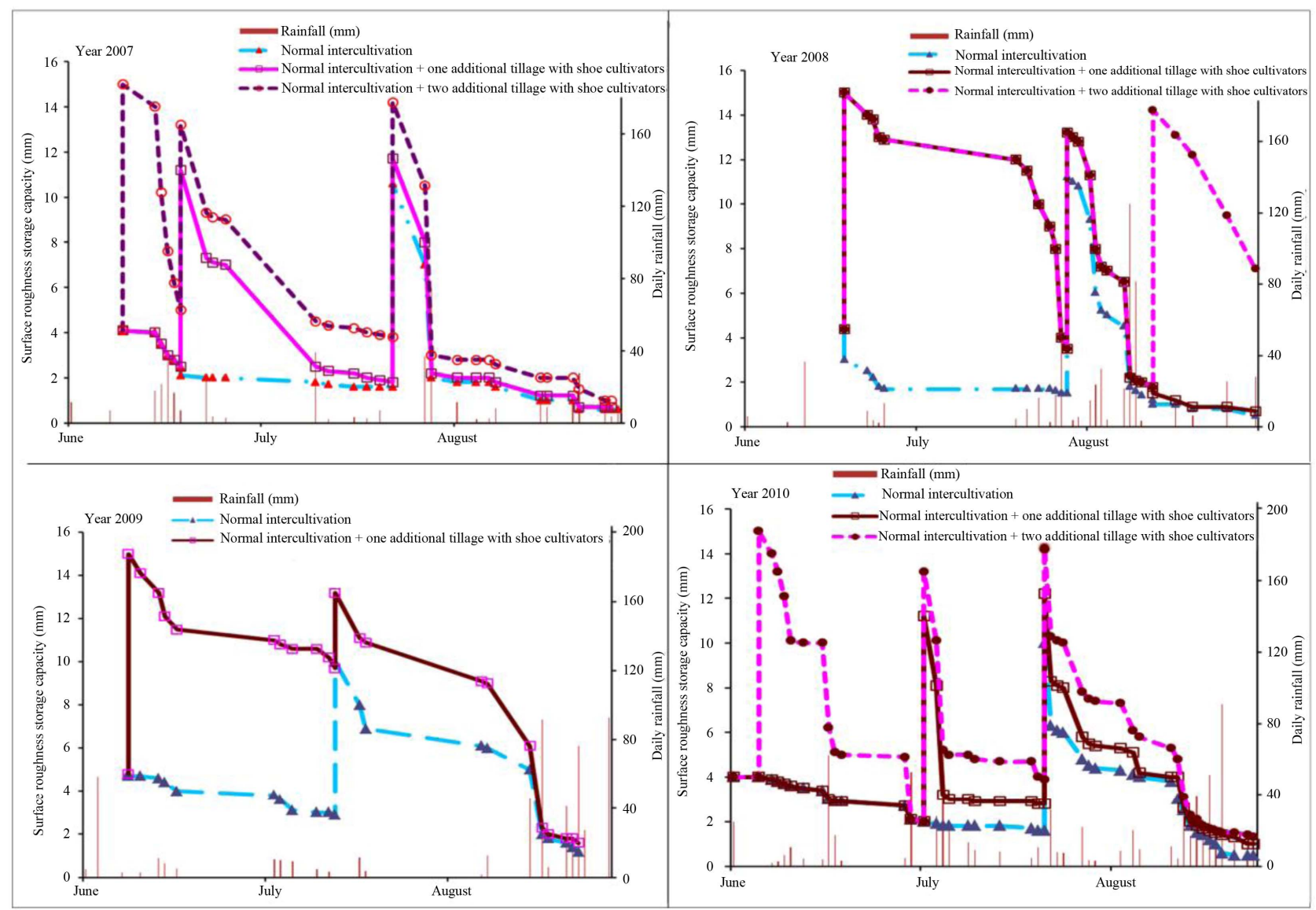

Figure 3. Changes in the surface depression storage capacity (simulated values) from the different inter-row tillage systems on Alfisols during 2007-2010.

Table 5. Effects of different inter-row tillage systems on sorghum yield on Alfisol watersheds, ICRISAT center, Patancheru, India, 2007-10.

\begin{tabular}{|c|c|c|c|c|c|}
\hline \multirow{2}{*}{ Tillage treatment } & \multicolumn{5}{|c|}{ Sorghum grain yield $\left(\mathrm{t} \cdot \mathrm{ha}^{-1}\right)^{*}$} \\
\hline & 2007 & 2008 & 2009 & 2010 & Mean of $2007-10$ \\
\hline Normal intercultivation & 2.11 & 3.65 & 1.67 & 2.62 & 2.51 \\
\hline Normal intercultivation + one additional tillage with shoe cultivators ${ }^{*}$ & 2.66 & 3.96 & 2.16 & 2.79 & 2.89 \\
\hline Normal intercultivation + two additional tillage with shoe cultivators ${ }^{*}$ & 2.89 & 4.12 & 2.25 & 2.76 & 3.00 \\
\hline $\mathrm{SE} \pm$ & 0.193 & 0.286 & 0.204 & 0.272 & 0.238 \\
\hline
\end{tabular}

"Simulated values.

in results observed in the plot scale experiment.

\section{CONCLUSION}

On SAT Alfisols due to crusting and sealing problems, the high runoff during the early part of the cropping season is one of the major problems, leading to low and unsustainable crop yields. The inter-row tillage in addition to normal intercultivation is found to be effective in controlling the early season runoff and soil loss and increasing crop yields. During the low and medium rainfall years, the additional tillage system is found to be highly effective in reducing runoff and soil loss and increasing crop yields. During high rainfall years with good rainfall distribution, the additional tillage is not so effective in increasing crop yields but moderately effective in reducing runoff. The additional tillage with shoe cultivators, which creates rough soil surface with large clods, is found to be most effective in increasing crop yields and controlling runoff and soil loss. The additional tillage with blade harrow which generally leaves smooth soil 
surface with fine and pulverized soil is relative less effective than the additional tillage with shoe cultivators. In most rainfall situations, the normal intercultivation with one additional tillage was adequate for controlling early season runoff and improving soil moisture and crop yields. An additional tillage treatment might marginally increase the crop yields, but this would result in higher soil loss especially during high rainfall conditions.

\section{ACKNOWLEDGEMENTS}

The authors are thankful to Dr. K L Sahrawat, Consultant, Resilient Dryland Systems, ICRISAT, for his comments and suggestions on the paper. We also acknowledge the contribution of Mr. L J Naidu Technical Officer, Resilient Dryland Systems, ICRISAT, in collecting the data from the experiments.

\section{REFERENCES}

[1] Hussein, M.H., Awad, M.M. and Abdul-Jabbar, A.S. (2010) Effect of surface crust on rainfall infiltration in an Aridisoil in northern Iraq. European Water, 32, 25-34.

[2] Philip, J.R. (1998) Infiltration into crusted soils. Water Resources Research, 34, 1919-1927. doi:10.1029/98WR01207

[3] Cary, J.W. and Evans, D.D. (1974) Soil crusts. In: Cary, J.W. and Evans, D.D., Eds., Technical Bulletin, University of Arizona, Agricultural Experiment Station, Tuscon, $58 \mathrm{pp}$.

[4] Assouline, S. (2004) Rainfall-induced soil surface sealing: A critical review of observations, conceptual models and solutions. Vadose Zone Journal, 3, 570-591. doi:10.2113/3.2.570

[5] Assouline, S. and Mualem, Y. (2003) Effects of rainfallinduced soil seals on the soil water regime: Drying intervals and subsequent wetting. Transport in Porous Media, 53, 75-94. doi:10.1023/A:1023583808812

[6] Tarchitzky, J., Banin, A., Morin, J. and Chen Y. (1984) Nature, formation and effects of soil crusts formed by water drop impact. Geoderma, 33, 135-155. doi:10.1016/0016-7061(84)90025-9

[7] Valentin, C. and Bresson, L.M. (1992) Soil crust morphology and forming processes in loamy and sandy soils. Geoderma, 55, 225-245. doi:10.1016/0016-7061(84)90025-9

[8] Wakindiki, I.I.C. and Ben-Hur, M. (2002) Soil mineralogy and texture effects on crust micromorphology, infiltration and erosion. Soil Science Society of America Journal, 66, 897-905. doi:10.2136/sssaj2002.0897

[9] El-Swaify, S.A., Walker, T.S. and Virmani, S.M. (1984) Dryland management alternatives and research needs for Alfisols in the semi-arid tropics. Consultant's Workshop on the State of the Art and Management Alternatives for Optimizing to Productivity of SAT Alfisols and Related Soils, ICRISAT Center, 1-3 December 1983, 44 pp.

[10] Pathak, P., Sudi, R., Wani, S.P. and Sahrawat, K.L. (2013) Hydrological behavior of Alfisols and Vertisols in the semi-arid zone: Implications for soil and water management. Agricultural Water Management, 118, 12-21. doi:10.1016/j.agwat.2012.11.012

[11] Stolte, J., Ritsema, C.J. and Roo, A.P.J. (1997) Effects of crust and cracks on simulated catchment discharge and soil loss. Journal of Hydrology, 195, 279-290. doi:10.1016/S0022-1694(96)03249-0

[12] Pathak, P. and Sudi, R. (2004) Manual of operation and instruction: Microprocessor-based automatic sediment sampler. Global Theme on Agroecosystems, ICRISAT, Patancheru.

[13] Pathak, P., Laryea, K.B. and Sudi, R. (1989) A runoff model for small watersheds in the semi-arid tropics. Transactions of the ASAE, 32, 1919-1624.

[14] Ritchie, J.T. (1998) Soil water balance and plant water stress. In: Tsuji, G.Y., Hoogenboom, G. and Thornton, P.K., Eds., Understanding Options for Agricultural Production, Kluwer Academic Publishers, London, 41-54. doi:10.1007/978-94-017-3624-4 3 